\title{
Proximal Circumflex Artery
}

National Cancer Institute

\section{Source}

National Cancer Institute. Proximal Circumflex Artery. NCI Thesaurus. Code C102331.

The section of the left circumflex coronary artery that arises from the left main coronary artery and extends to the first marginal branch. 